\title{
Role of ICT on the Academic Achievement of Madrasa Students
}

\author{
Nikhat \\ Assistant Professor, Department of Education \\ Citizen Girls College, Naini, Allahabad India \\ E-mail: nikhatjahan08@gmail.com
}

\begin{abstract}
Zebun Nisa Khan
Associate Professor, Department of Education

Aligarh Muslim University, Aligarh 202002 India

Visiting Faculty, Centre of International Education

University of Massachusetts, Amherst MA, USA

E-mail: zebunnisakhan@yahoo.com
\end{abstract}

Received: June 2, $2020 \quad$ Accepted: June 27, $2020 \quad$ Published: June 29, 2020

doi: 10.5296/ire.v8i2.17277 URL: https://doi.org/10.5296/ire.v8i2.17277

\begin{abstract}
In the present study, investigators tried to find out the role of ICT on the academic achievement of Madrasa students in Aligarh district. The study was conducted with the objective to determine whether ICT is helping to improve the academic achievement of the students in relation to demographic variables as gender and Socio-economic status. The sample comprising of 380 students of both experimental group and control group were selected through randomized sampling procedure. The experimental groups taught with ICT while the control group with the traditional method. The statistical techniques used in the study was descriptive analysis and independent t-test. The findings of the study showed that after treatment the experimental group perform better in the academic learning as compared to the control group in both demographic variables as gender and Socio-economic status.
\end{abstract}

Keywords: Academic achievement, Madrasa students, Socio-economic status, Demographic, Information and Communication Technologies (ICT), Kindle complex content, Cognitive. 


\section{Introduction}

In the last few decade it was observed that the education which was carried out in the four wall of the room was unable to cater the requirement of the children in all walks of life therefore, the emergence of new technology is the need of the hour which will help and assist the teaching and learning process. The Introduction to the Primary School Curriculum states: Technological skills are increasingly important for advancement in education, work, and leisure. The curriculum integrates ICT into the teaching and learning process and provides children with opportunities to use modern technology to enhance their learning in all subjects Primary School Curriculum (1999, p. 29). One cannot provide best learning environment unless and until to provide education with the help of Information and Communication Technologies (ICT). In the recent digital generation, the learning process more or less depends upon ICT. ICT is the medium, which is helpful to present different phenomenon, and processes vibrantly, kindle complex content and most important it is helpful to present diverse stages of abstraction. This is helpful in significant and reliable learning. The learning performance of students has been greatly influenced by rapid advances in ICT. Moore (2005) in his study found that there is positive impact of ICT on pupil's learning such as increased student's motivation to stay on-task and drive them to behave better and produce high quality work. It was found that integration of this ICT in classroom helps to create an environment for student's activities that lead to meaningful and sustainable learning experiences. It supports students in their own constructive thinking, allows them to transcend their cognitive limitations. It is possible to bring the process of learning beyond the boundaries of classroom by exploring new possibilities of ICT. One of the basic requirements for education in this era of information explosion is to prepare learners for participation in a networked information society. All over the world, educational institutions are being forced to find better pedagogical methods to cope up with these new challenges.

The impacts of ICT upon academic achievement of students have been studied by lots of investigators. Cook and Finlayson (1999) found that if ICT used is increased in the community then students get more experiences and prospect which will be helpful for them to increase learning experiences. Norzita (2004) revealed that the minimum level of the skill of using computers and ICT amongst teachers in teaching and learning of Science was high. Sutherland et al. (2004) analyzed that the use of ICT will be helpful to enhance learning among students if teachers used good lesson plan to enhance learning activities among students. Students must be encouraged to understand the process involved. Fun (1990) performed a study on the attitudes of the Form Six students during computer-aided activities in Geography classes. This study showed that students have positive attitudes towards the use of computer, which was considered as an effective technique of teaching and learning pedagogy by students. Kubiatko (2010) found that the attitudes of students toward ICT use in teaching and learning Science subject among high school students were based on statistical evaluation. Students seemed interested in using ICT in the Science subjects. The same study also concluded that ICT could enhance student's learning in Science from early age. Khan (2010) found that CAI method was more effective than the traditional method in teaching Civics at class IX level. The study demonstrated that CAI produced significant positive difference in the achievement on the knowledge, comprehension and application aspects. 
Khan (2010) developed a software on the concept of Modernization in the subject of Civics as CAI package for class IX students. Tonui et al. (2016) is of the opinion that the process of integrating ICT in teaching-learning in primary schools is still riddled with challenges, notably unavailability of power, infrastructure, computers, lack of procedures for monitoring and evaluating ICT use, and inadequate capacity building. Essays, UK. (November 2018) author is of the opinion that children interacting at computers retain high stages of communication and co-operation skills. Using computers in the primary school can help children's literacy development.

There are so many studies conducted to assess the influence of ICT on the academic achievement of school students but not a single experimental study conducted to check the academic performance of Madrasa students that is why the investigators conducted pre-test and post-test control experimental study upon Madrasa students of Aligarh district of Uttar Pradesh.

\section{Significance of the Study}

According to Census 2011, the population of Muslim in India is $14.23 \%$, in which around 2\% of children are studying in Madrasa. Sacchar report (2005) clearly indicate that Muslims are educationally backward as compared to the SC/ST and only 4\% of the Muslims population are able to pursue higher education that means the education they are getting does not match with the present scenario. After reviewing so many related literatures it was found that education given in the Madrasa are only able to develop lower cognitive domain i.e., knowledge and understanding because they only focus on the rote memorization and unable to achieve higher cognitive domain i.e., Analysis and create. If we want to make them productive contributor of society then they should be taught with the help of advanced technology. The present study is an attempt to analyses the role of ICT on learning performance of the Madrasa students. The study will be useful for the policy makers in the field of Science education, Madrasa curricular developers, teachers, parents and students also. It will also be helpful for the Madrasa teachers and administrators to develop a strategy for effective teaching and snatch attention of all sectors for the upliftment of Madrasa students and for further researches in the field.

Information and Communication Technology: In the present context of the study, the ICT were used in the form of pictures, animation video clips, along with the other graphics, included in the ppt lesson plan prepared.

Academic Achievement: On the basis of achievement the investigators have checked test of Science Academic Achievement of Madrasa students.

Madrasa: Madrasa includes all those Madrasas in Aligarh district, which were teaching Science in English medium.

Socio-economic Status: The total score obtained by individual students on the Socio-economic Status Scale (Urban and Rural) developed and standardized by Kalia and Sahu.

Variables used in the study: Independent variables: ICT, traditional teaching, gender and SES Dependent variable: Academic achievement. 


\section{Objectives of the Study}

In the present study, following objectives are framed:

- to compare the academic achievement score of the experimental group and the control group before treatment (pre-test).

- to compare the academic achievement score of the experimental group and the control group after treatment (post-test).

- to compare the academic achievement score of the male and female students of experimental and control group.

- to compare the academic achievement score of the students having high and low SES.

\section{Hypothesis of the Study}

The following hypothesis were framed:

- there is no significant difference between the academic achievement score of the experimental group and the control group before treatment (pre-test).

- there is no significant difference between the academic achievement score of the experimental group and the control group after treatment (post-test).

- there is no significant difference between the academic achievement score of the male and female students of experimental and control group.

- there is no significant difference between the academic achievement score of the students having middle and low SES.

\subsection{Research Methodology}

A pre-test and post-test control group experimental design were used by randomized technique on the selected Madrasa students of Aligarh district, India.

\subsection{Population, Sample and Sampling Technique}

Class Sixth students studying in Government and non-government aided twelve Madrasa of Aligarh District constitute the population. The sample consisted of 380 students in which 190 students were taken from male Madrasa and 190 students were taken from female Madrasa through Purposive Random Sampling.

\subsection{Tool Used in the Study}

\subsubsection{Achievement Test}

Investigators developed achievement test in Science for both pre-test and post-test. Both the achievement tests SAT1 and SAT2 were developed and validated to collect data from both groups to check their learning performance. Items were finalized after item analysis. Reliability of SAT1 and SAT2 were 0.78 and 0.72 respectively. Both tests consist of 45 items of multiple choice having an option correct. The items were developed on the basis of revised blooms taxonomy in which we only select three domains i.e., remember, understand and apply. 
Table 1. Cognitive domain wise distribution of MCQ items of Achievement test (SAT1 and SAT2)

\begin{tabular}{lll}
\hline Domain & No of items & Percentage (\%) \\
\hline Remember & 25 & 55 \\
Understand & 10 & 22 \\
Apply & 10 & 22 \\
\hline
\end{tabular}

\subsubsection{Socio-economic Status Scale}

The total score obtained by individual students on the Socio-economic Status Scale (Urban and Rural) developed and standardized by Kalia and Sahu.

\subsubsection{Lesson Plan of Traditional Method}

A lesson plan was prepared on 8 units of Science textbook of class Sixth on traditional line where chalk and talk method was used.

\subsubsection{Lesson Plan of ICT Method}

A lesson plan was prepared on 8 units of Science textbook of class sixth on the basis of ICT method in which different pictures, animations and video clips along with other graphics such as ppt were included.

\section{Procedure of the Study}

After classifying the sections into two parts i.e., control group and experimental group, following steps were used:

Step 1: Pre-testing stage: SAT1 was administered in sections of both groups to collect and compare the score of the students before treatment.

Step 2: Treatment stage: Control group was taught with lesson plan based on traditional method i.e., chalk and talk while experimental group was taught with lesson plan based on ICT method i.e., with the help of ppt, different pictures, animations and video clip.

Step 3: Post-testing stage: SAT2 was administered in sections of both groups to collect and compare the score of the students after treatment.

Table 2. Representation of group treatments at pre-test and post-test

\begin{tabular}{llll}
\hline Group & Pre-test & Treatment & Post-test \\
\hline Experimental Group & ST1 & ICT & ST2 \\
Control Group & ST1 & Traditional teaching & ST2 \\
\hline
\end{tabular}

In Table 2, it is clearly indicated that control group was taught with traditional method while experimental group was taught with ICT. ST1 represents Science Achievement Test 1 which were given to both i.e., control group and experimental group before treatment and ST2 represents Science Achievement Test 2 which were given to both control group and experimental group after treatment to measure achievement of Madrasa students in Science 
subject.

\section{Statistical Technique}

Mean, Std and independent t-test were used to compare the score of pre-test and post-test of control and experimental groups in all three independent samples. Descriptive and Differential Statistics was used for data analysis followed by software analysis through SPSS 16.0 .

\section{Result and discussion}

After collecting the data from Madrasa, the analysis of data was done by the investigators with the help of statistical technique to get best result.

Hypotheses 1: There is no significant difference in the achievement score of the experimental group and the control group before treatment.

Table 3. Comparison of academic achievement score of the experimental group and the control group before treatment (pre-test)

\begin{tabular}{llllll}
\hline Group & $\mathrm{N}$ & Mean & Df & t-value & Level of significance \\
\hline Experimental group & 190 & 11.95 & & & Not Significant, difference at \\
Control group & 190 & 12.85 & 78 & 1.312 & 0.05 levels. \\
\hline
\end{tabular}

As shown in Table 3, when experimental group were compared with the students of control group, the calculated value $(\mathrm{t}=1.312)$ was found not to be significant at 0.05 level of confidence. The in-depth study investigation reveals that when the students of experimental group were compared with the students of control group the mean value of experimental group ( $M 1=11.95)$ was not much higher than the mean value of control group ( $M 2=12.85)$. Hence, the Hypothesis 1 was accepted. These results clearly showed that there was no significant difference between the academic achievement score of students of experimental group and students of control group at pre-test.

Hypotheses 2: There is no significant difference in the achievement score of the experimental group and the control group after treatment (post-test).

Table 4. Comparison of academic achievement score of the experimental group and the control group after treatment (post-test)

\begin{tabular}{llllll}
\hline Group & $\mathrm{N}$ & Mean & Df & t-value & Level of significance \\
\hline $\begin{array}{l}\text { Experimental } \\
\text { group }\end{array}$ & 190 & 23.47 & & & $\begin{array}{l}\text { Significant difference at } 0.05 \\
\text { levels }\end{array}$ \\
Control group & 190 & 18.75 & & 10.60 & \\
\hline
\end{tabular}

As shown in Table 4, when experimental group were compared with the students of control group, the calculated value $(\mathrm{t}=10.60)$ was found to be significant at 0.05 level of confidence. 


\section{Macrothink}

The in-depth study investigation reveals that when the students of experimental group were compared with the students of control group the mean value of experimental group $(\mathrm{M} 1=23.47)$ was much higher than the mean value of control group (M2=18.75). Hence, the Hypothesis 2 was rejected. These results clearly showed that there was significant difference between the academic achievement score of students of experimental group and students of control group at post-test.

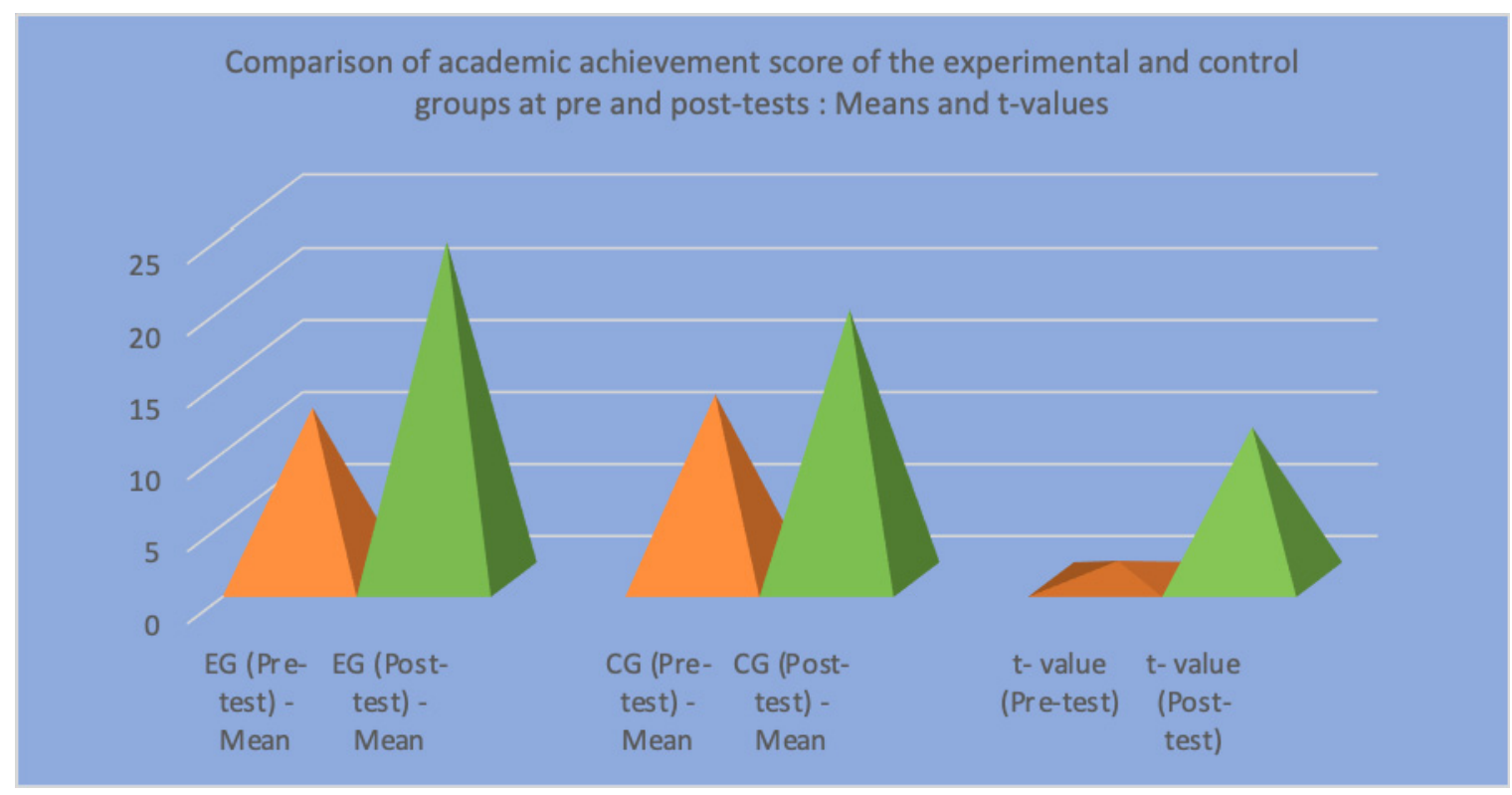

Figure 1. Comparison of academic achievement score of the experimental and control groups at pre and post-tests: means and t-values

Hypotheses 3: There is no significant difference in the achievement score of the male and female students.

Table 5. Comparison of academic achievement score of the male and female students

\begin{tabular}{llllll}
\hline Gender & $\mathrm{N}$ & Mean & Df & t-value & Level of significance \\
\hline Male group & 190 & 12.72 & & & $\begin{array}{l}\text { Not Significant difference at } \\
0.05 \text { levels }\end{array}$ \\
Female group & 190 & 12.05 & 78 & 1.008 &
\end{tabular}

As shown in Table 5, when male student was compared with the female students, the calculated $t$-value $(t=1.008)$ was not found to be significant at 0.05 level of confidence. The in-depth study investigation reveals that when male student was compared with the female students, the mean value of male students $(M 1=12.72)$ was much higher than the mean value of female students $(\mathrm{M} 2=12.05)$. Hence, the Hypothesis 3 was accepted. These results clearly showed that there is no significant difference between the academic achievement score of students of male and female students. 


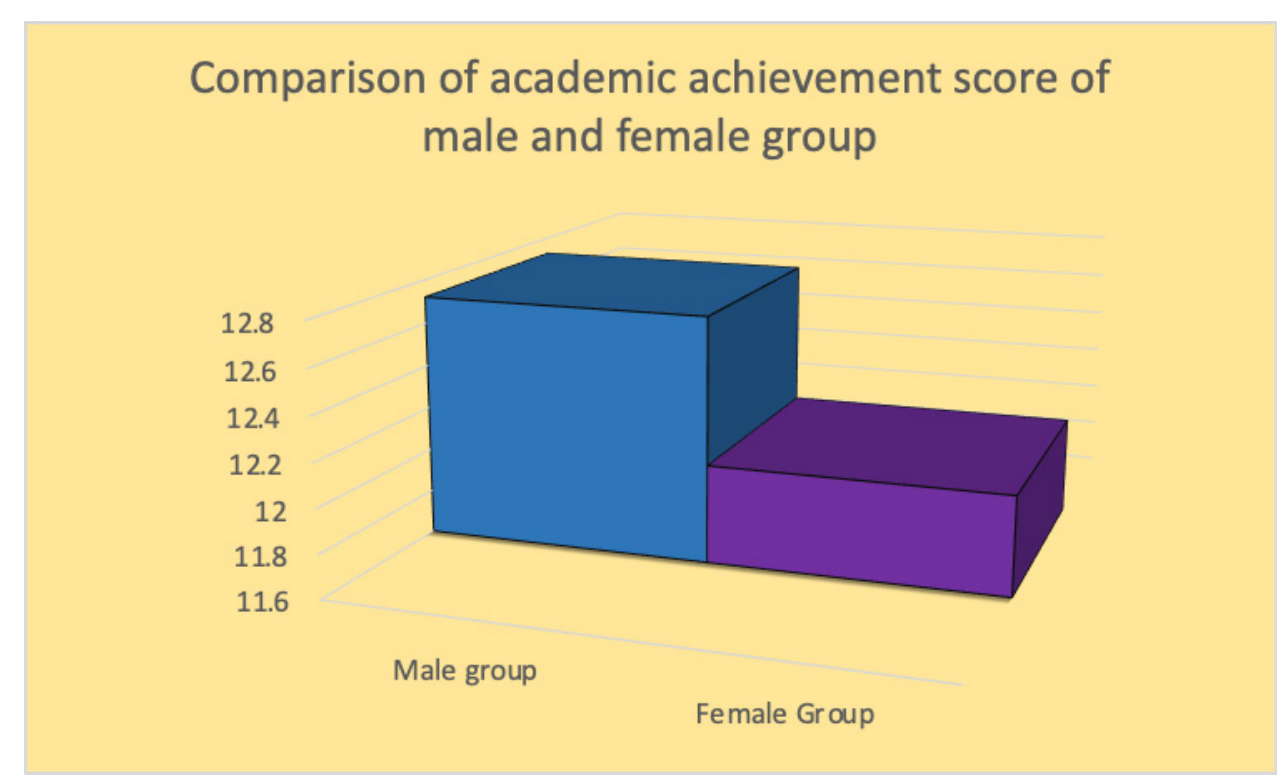

Figure 2. Comparison of academic achievement score of male and female group

Hypotheses 4: There is no significant difference in the achievement score of the lower socio-economic status and middle socio-economic status.

Table 6. Comparison of academic achievement score between lower and middle socio-economic status

\begin{tabular}{lllcll}
\hline Socio-economic Status & $\mathrm{N}$ & Mean & Df & t-value & Level of significance \\
\hline Lower SES group & 122 & 20.41 & & & Significant difference \\
Middle SES group & 258 & 22.95 & 78 & 3.851 & at 0.05 levels \\
\hline
\end{tabular}

As shown in Table 6, when lower Socio-economic status students were compared with the students of middle Socio-economic status, the calculated $t$-value $(t=3.851)$ was found to be significant at 0.05 level of confidence. The in-depth study investigation reveals that the mean value of middle Socio-economic status (M2=20.41) was much higher than the mean value of lower Socio-economic status students $(M 1=22.95)$. Hence, the Hypothesis 4 was rejected. It clearly shows that there is a significant difference between the academic achievements score of lower Socio-economic status students in comparison to the middle Socio-economic status students. 


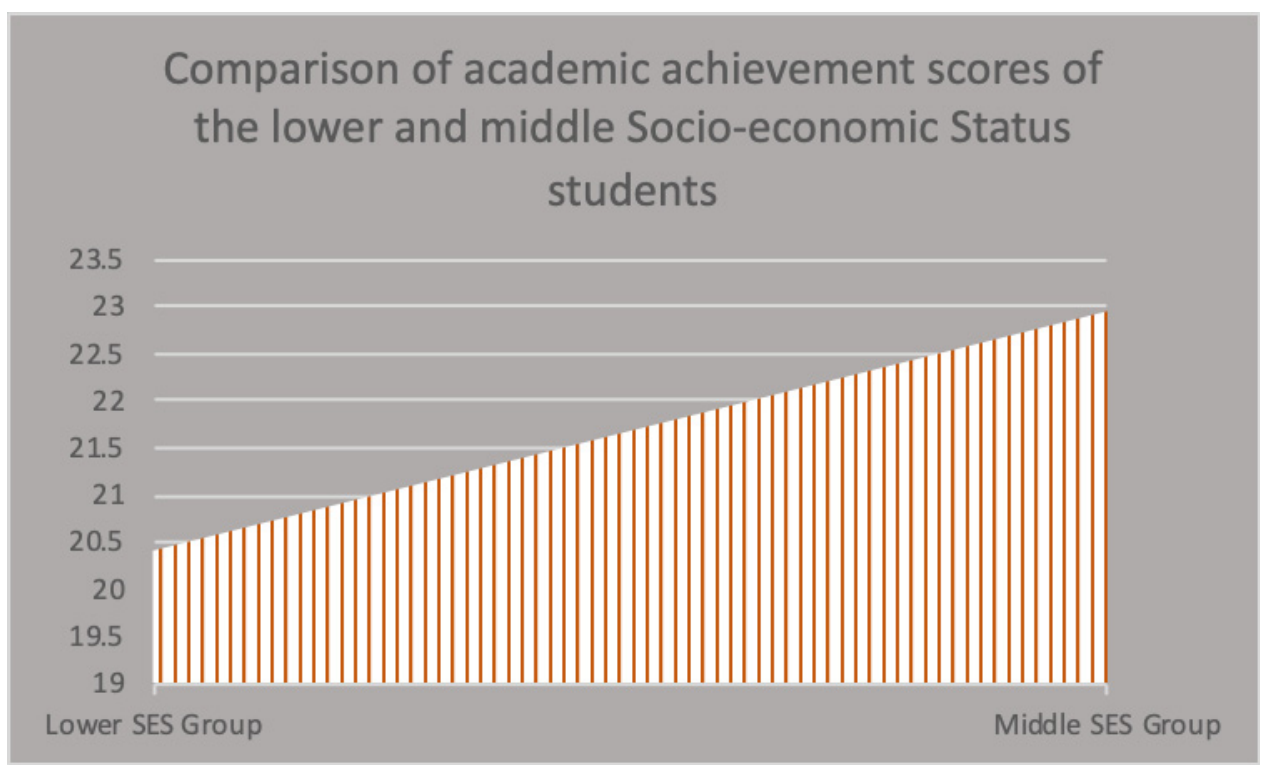

Figure 3. Comparison of academic achievement scores of the lower and middle socio-economic status students

\section{Conclusion}

The result of the study showed that there was a strong correlation between the use of ICT in teaching and learning with Madrasa student's achievements in Science. According to the findings of this study, student's achievements increased when ICT is used in a lesson as compared to the traditional method of teaching. It was also found that students performed well in Science subject when they were taught with multimedia approach i.e., ICT. ICT used in lessons especially in the Science subject produced higher quality output of students. It is thus concluded that if Madrasa students were taught with advanced media they will perform better in other subjects and can be included in the mainstream easily and bring significant changes in our culture.

Educational Implications

1). Madrasa teachers should start using teaching with the help of computer, which is helpful for creating interest and motivation among students.

2). With the help of ICT, the students will be able to attains higher cognitive domains i.e., evaluation, analyze and create.

3). The government should provide necessary Advanced Multimedia Devices to Madrasa and supervise after every six months to check whether it is properly used or not.

\section{References}

Cook, D., \& Finlayson, H. (1999). Interactive Children, Communicating Teaching ICT and Classroom Teaching. Buckingham: Open University Press.

Fun, F. Y. (1990). Form Six Students' Attitudes in Two Schools on the Learning Games Program Involved Computer Aided in Geography Classes. http://www.bidang pengajian (accessed 28 July 2007) 


\section{Macrothink}

International Research in Education

ISSN 2327-5499

2020, Vol. 8, No. 2

Khan, Z. N. (2010). Relative Effectiveness of Computer Assisted Instruction and Traditional Method of Teaching at Secondary School Level. Ubiquitous Learning (USA), 2(1), 111-118. https://doi.org/10.18848/1835-9795/CGP/v02i01/40443

Kubiatko, M. (2010). Czech University Students' Attitudes Towards ICT Used in Science Education. Journal of Technology and Information Education, 2(3). https://doi.org/10. 5507/jtie.2010.042

Moore, C. D. (2005). Is ICT Being Used to its Potential to Improve Teaching and Learning Across the Curriculum? Retrieved from http://www.teacherresearch.net.

Mudasir, H. \& Shah, W. (2015). ICT as a Tool for Teaching Learning Process and Achievement in Subjects of High School Students in District Kulgam. New York Science Journal, 8(2), 48-54.

Norzita, M. D. (2004). Review of the Implementation of the Willingness of Teachers in Teaching of Science and Mathematics in English. Master's project paper of education, Universitiy Kebangsaan Malaysia.

Sutherland et al. (2004). Transforming Teaching and Learning: Embedding ICT into Everyday Classroom Practices. Journal of Computer Assisted Learning, 20, 413-425. https://doi.org/10.1111/j.1365-2729.2004.00104.x

Tonui, B. et al. (2016). An Investigation into Implementation of ICT in Primary Schools, in Kenya, in the Light of Free Laptops at Primary One: A Case Study of Teachers Implementing ICT into their Teaching Practice. Journal of Education and Practice, 7(13), 12-16.

\section{Copyright Disclaimer}

Copyright reserved by the authors.

This article is an open-access article distributed under the terms and conditions of the Creative Commons Attribution license (http://creativecommons.org/licenses/by/4.0/). 